\title{
Polymorphisms in MicroRNA Target Sites of TGF- $\beta$ Signaling Pathway Genes and Susceptibility to Allergic Rhinitis
}

\author{
Ruo-Xi Chen ${ }^{a}$ Wen-Min Lu ${ }^{b}$ Mei-Ping Lu ${ }^{a}$ Mei-Lin Wang ${ }^{c}$ Xin-Jie Zhu ${ }^{a}$ \\ Zhong-Fei Wu $^{\text {a Hui-Qin Tian }}{ }^{\text {a }}$ Lu-Ping Zhu ${ }^{d}$ Zheng-Dong Zhang ${ }^{c}$ \\ Lei Cheng ${ }^{\mathrm{a}} \mathrm{e}$
}

\begin{abstract}
aDepartment of Otorhinolaryngology and Clinical Allergy Center, The First Affiliated Hospital, Nanjing Medical University, Nanjing, China; ${ }^{b}$ Department of Otorhinolaryngology, The Affiliated Changzhou No. 2 People's Hospital, Nanjing Medical University, Changzhou, China; ' Department of Genetic Toxicology, The Key Laboratory of Modern Toxicology of Ministry of Education, Center for Global Health, School of Public Health, Nanjing Medical University, Nanjing, China; dDepartment of Otorhinolaryngology, The Second Affiliated Hospital, Nanjing Medical University, Nanjing, China; 'International Centre for Allergy Research, Nanjing Medical University, Nanjing, China
\end{abstract}

\section{Keywords}

Allergic rhinitis - MicroRNAs · Single-nucleotide polymorphism - Transforming growth factor beta $\cdot$ Genetic association studies

\begin{abstract}
Background: The polymorphisms inside microRNA target sites locating in the $3^{\prime}$-UTR region may introduce the microRNA-binding changes, which may regulate the gene expression and correlate with the potential diseases. Objectives: We aimed to investigate whether the polymorphisms in microRNA target sites of transforming growth factor beta (TGF- $\beta$ ) signaling pathway genes are associated with the susceptibility of mite-sensitized allergic rhinitis (AR) in a Han Chinese population. Methods: In this case-control study, 454 AR patients and 448 healthy controls were recruited. Three HapMap single-nucleotide polymorphisms (SNPs) were mapped to putative microRNA recognition sites and genotyped by TaqMan allelic discrimination assay. Results: The genotype and allele frequencies of 3 SNPs (rs1590 in TGFBR1; rs1434536 and rs17023107 in BMPR1B) showed lack of significant association with AR. However, in the subgroup analysis, the TG, GG, and TG/GG genotypes of rs1590 exhibited
\end{abstract}

karger@karger.com www.karger.com/iaa

Karger

GOPEN ACCESS
(C) 2021 The Author(s)

Published by S. Karger AG, Basel

This is an Open Access article licensed under the Creative Commons Attribution-NonCommercial-4.0 International License (CC BY-NC) (http://www.karger.com/Services/OpenAccessLicense), applicable to the online version of the article only. Usage and distribution for commercial purposes requires written permission. significantly increased risk of AR in the male subgroup (TG: adjusted $\mathrm{OR}=1.57,95 \% \mathrm{Cl}=1.08-2.31$; GG: adjusted $\mathrm{OR}=$ $1.76,95 \% \mathrm{Cl}=1.09-2.86 ; \mathrm{TG} / \mathrm{GG}$ : adjusted $\mathrm{OR}=1.62,95 \%$ $\mathrm{Cl}=1.13-2.33)$. The $\mathrm{CT}$ genotypes of $\mathrm{rs} 17023107$ might have potential to protect against $A R$ in the patients age of $<15$ years (adjusted $\mathrm{OR}=0.37,95 \% \mathrm{Cl}=0.14-0.95$ ) and the males (adjusted $\mathrm{OR}=0.48,95 \% \mathrm{Cl}=0.25-0.95$ ). No significant association was found between SNPs and the total serum IgE level. Conclusions: In a Han Chinese population, stratified by age and gender, susceptibility to mite-sensitized AR may be associated with 2 SNPs (rs1590 and rs 17023107) in microRNA target sites of TGF- $\beta$ signaling pathway genes.

(c) 2021 The Author(s)

Published by S. Karger AG, Basel

\section{Introduction}

Allergic rhinitis (AR) affects $10-42 \%$ of the population worldwide [1]. The prevalence of adult AR in China increased from $11.1 \%$ in 2005 to $17.6 \%$ in 2011 in major cities [2-4]. As a heterogeneous disorder of the nasal mu-

Ruo-Xi Chen and Wen-Min Lu contributed equally to this work. Edited by: D.Y. Wang, Singapore. 
cosa, AR is induced by T helper 2 cells and IgE responses that are specific to aeroallergens in allergen-sensitized individuals. Since the 1990s, genetic studies using the candidate gene approaches have found linkage between cytokine-encoding genes and other immunomodulatory mediators $[5,6]$.

Transforming growth factor beta (TGF- $\beta$ ) is a pleiotropic cytokine that directs cellular responses including proliferation, differentiation, apoptosis, migration, tissue repair, and immunoglobulin isotype switching [7]. Dysfunction of TGF- $\beta$ signaling pathway shows intimacy with multiple human disorders, such as cancer, asthma, autoimmune, and cardiovascular diseases $[8,9]$. TGF- $\beta$ superfamily is a composite of fibrogenic and immunomodulatory factors propping up the structure of the upper and lower airways $[10,11]$. The elevated levels of TGF- $\beta 1$ could act as a healing molecule in the airways of asthmatics, promoting the process of tissue repair [12] and diminishing airway hyperresponsiveness [13]. A cytosine to thymine transition within the TGFB1 promoter (rs1800469) has been reported significantly associated with a higher plasma concentration of TGF- $\beta 1$ [14] in the development of asthma $[15,16]$ Moreover, our previous study has confirmed that rs1800469 in TGFB1 is associated with increased risk and severity of persistent $A R$ in a Chinese population [17]. Allelic variations in the constituents of TGF- $\beta$ pathway may regulate transcription and expression of target genes and proteins, which in turn changes the function of TGF- $\beta$ pathway and the process of allergic diseases.

MicroRNAs are a class of endogenous short noncoding RNAs (18-25 nt long) that act posttranscriptionally as negative regulators in gene expression principally via interaction with target sites in the $3^{\prime}$-UTRs of regulated genes in metazoans [18]. The introduction of a singlenucleotide polymorphism (SNP) into a $3^{\prime}$-UTR can have numerous functional consequences potential associated with human disorders, by either introducing or removing microRNA target sequences or changing the binding efficiency [19]. Studies have shown that C minor allele (SNP rs4245739A $<$ C) in the $3^{\prime}$-UTR of $M D M 4$ has been shown to decrease the risk of cancer, as the $\mathrm{C}$ minor SNP creates a new binding site for miR-191 and/or miR-887$3 p[20,21]$. On the other hand, it was known that miR498, miR-155, miR-205, and let-7e may play a role in development of $\mathrm{AR}[22,23]$. Experimentally validated results suggested a bidirectional cross-talk between microRNAs and TGF- $\beta$ pathway [18], as evidenced by the role of miR-146a polymorphism in asthma [24, 25]. This study was undertaken, for the first time, to evaluate the associations between SNPs in the putative microRNA target sites of $3^{\prime}$-UTR of TGF- $\beta$ signaling pathway genes and the susceptibility to mite-sensitized AR in a Han Chinese population.

\section{Materials and Methods}

\section{Subjects}

A total of $454 \mathrm{AR}$ patients (304 males and 150 females) were recruited from the First Affiliated Hospital of Nanjing Medical University since May 2008. AR was diagnosed according to the ARIA 2008 update [26]. The presence of other allergic diseases, like asthma, eczema, atopic dermatitis, urticaria, and food and drug allergies, as well as a family history of allergy was determined according to a questionnaire. Patients enrolled were sensitized mainly by dust mites, including Dermatophagoides pteronyssinus (Der p) or Dermatophagoides farinae (Der $f$ ). According to the questionnaire results, $105 \mathrm{AR}$ (23.1\%) patients were accompanied with asthma, and 272 (59.9\%) patients without asthma; 77 (17.0\%) patients' asthma information was missing because the related items in their questionnaires were not answered. The 448 healthy controls (277 males and 171 females) were recruited from the annual physical exams, which confirmed that they had normal nasal examination, no clinical features of nasal diseases, and no clinical features or family history of allergy. The Phadiatop assay exhibited negative allergen-specific IgE in their serum. Age and gender of the patients and the controls were matched. The response rate in the study was $>85 \%$. After the interview, $5 \mathrm{~mL}$ peripheral blood was taken by venipuncture from each subject. However, in all cases before taking peripheral venous blood, glucocorticoids were not used within 4 weeks; $\mathrm{H} 1$ antihistamines, leukotriene receptor antagonists, and other antiallergic drugs were not used within 2 weeks. The study was approved by the Ethics Committee of Nanjing Medical University (20080305). Written informed consent was obtained from all participants who were genetically unrelated Han Chinese from Jiangsu and Anhui provinces in eastern China.

\section{Quantitative IgE Measurements}

Serum total IgE and specific IgE were measured by the ImmunoCAP system (Phadia, Uppsala, Sweden). Total IgE was determined in all the subjects. Phadiatop tests were performed in the healthy controls. Specific IgE antibodies to common aeroallergens were determined in the patients, including $\operatorname{Der} p(\mathrm{~d} 1), \operatorname{Der} f(\mathrm{~d} 2)$, cat epithelium and dander (e1), dog dander (e5), Blatella germanica (i6), Alternaria alternate (m6), Ambrosia elatior (w1), and Artemisia vulgaris (w6). When the serum allergen-specific IgE was higher than $0.35 \mathrm{kUA} / \mathrm{L}$, the result was considered positive. We chose patients who are allergic to dust mites ( $\mathrm{d} 1 \mathrm{and} /$ or $\mathrm{d} 2$ ), a type of allergen that is the most common in East China. The positive rates of other aeroallergens (e1, e5, i6, m6, w1, and w6) were low and not the main allergens causing symptoms.

\section{Selection of Polymorphisms within the TGF- $\beta$ Signaling} Pathway

Forty-six potential SNPs derived from HapMap consortium were mapped to prospective microRNA target sites in 15 genes (TGFB1, TGFB2, TGFB3, TGFBR1, TGFBR2, TGFBR3, BMP2, BMP4, BMPR1A, BMPR1B, SMAD1, SMAD2, SMAD3, SMAD4, and SMAD7). The combined predictions by TargetScan [27], $\mathrm{Pa}-$ 
Table 1. Primers and probes for genotypes screening by TaqMan allelic discrimination

\begin{tabular}{llll}
\hline Target gene & SNPs & Primers & Probes \\
\hline TGFBR1 & \multirow{2}{*}{ rs1590 } & F: 5'-ACAAATGTGCTGACCCAAAGG-3' & C Allele: 5'-FAM-CATCATGCCCCACTG-MGB-3' \\
& & R: 5'-GGCTTTTCTCCACATGCTTAGG-3' & A allele: 5'-HEX-CATCATGCCCCAATG-MGB-3' \\
\hline BMPR1B & rs1434536 & F: 5'-TCCTTCTGGGAGCTTCTCTGTCT-3' & G allele: 5'-FAM-CTCCCTGAGAGGTGA-MGB-3' \\
& & R: 5'-TGCTTCCCAGTGGGTTCAG-3' & A allele: 5'-HEX-CTCCCTGAAAGGTGA-MGB-3' \\
\hline BMPR1B & rs17023107 & F: 5'-CCGCCTGTCTAGGACCACAT-3' & T Allele: 5'-FAM-TGGAATTCCTGTAGGTGG-MGB-3' \\
& & R: 5'-CATATTGCCTGAAGCTGCAAAA-3' & C Allele: 5'-HEX-TGGAATTCCTGCAGGTG-MGB-3' \\
\hline
\end{tabular}

Bold represents mutation sites. SNPs, single-nucleotide polymorphisms.

Table 2. Distribution of selected variables between cases and controls

\begin{tabular}{|c|c|c|c|c|c|}
\hline \multirow[t]{2}{*}{ Variables } & \multicolumn{2}{|c|}{ Cases $(n=454)$} & \multicolumn{2}{|c|}{ Controls $(n=448)$} & \multirow[t]{2}{*}{$p$ value } \\
\hline & $n$ & $\%$ & $n$ & $\%$ & \\
\hline Age, median (IQR), years & \multicolumn{2}{|c|}{$15.0(11.0-26.0)$} & \multicolumn{2}{|c|}{$15.5(9.9-29.0)$} & 0.890 \\
\hline \multicolumn{6}{|l|}{ Gender } \\
\hline Male & 304 & 67.0 & 277 & 61.8 & \multirow[t]{2}{*}{0.108} \\
\hline Female & 150 & 33.0 & 171 & 38.2 & \\
\hline \multicolumn{6}{|l|}{ Concomitant asthma $^{\mathrm{a}}$} \\
\hline Yes & 105 & 23.1 & & & \\
\hline No & 272 & 59.9 & & & \\
\hline Serum total IgE, median (IQR), kU/L & \multicolumn{2}{|c|}{$284.0(128.5-594.2)$} & \multicolumn{2}{|c|}{$25.0(10.4-47.4)$} & $<0.001$ \\
\hline \multicolumn{6}{|l|}{ Allergen-specific IgE, median (IQR), $\mathrm{kU}_{\mathrm{A}} / \mathrm{L}$} \\
\hline Dermatophagoides pteronyssinus & \multicolumn{2}{|c|}{$29.7(6.6-72.3)$} & & & \\
\hline Dermatophagoides farinae & \multicolumn{2}{|c|}{$24.6(6.2-66.9)$} & & & \\
\hline
\end{tabular}

Bold represents statistical significance. IQR, interquartile range. ${ }^{\text {a }}$ Information of concomitant asthma was unavailable in some cases.

trocles [28], PolymiRTS [29], and microRNA SNP [30], based on different biological parameters, empowered the identification of SNPs inside $3^{\prime}$-UTR that could potentially alter microRNA binding (referred to as target SNPs). Related documents published in MEDLINE/PubMed databases from January 2008 were reviewed, and 30 target SNPs were found. Consequently, 3 target SNPs in TGFBR1 (rs1590) and BMPR1B (rs1434536 and rs17023107) that may affect the binding affinity of microRNA::mRNA constituted the selection set to be genotyped. The primers and TaqMan probes are shown in Table 1.

\section{DNA Extraction and Genotyping}

Genomic DNA was purified from peripheral blood leukocytes using a commercial kit (Tiangen Biotech, Beijing, China) according to the manufacturer's instructions and stored at $-70^{\circ} \mathrm{C}$ until usage. Genotyping was performed with the TaqMan SNP Genotyping Assay using the 384-well ABI 7900HT Real-Time PCR System (Applied Biosystems, Foster City, CA, USA) with the following protocol: $50^{\circ} \mathrm{C}$ for $2 \mathrm{~min}, 95^{\circ} \mathrm{C}$ for $10 \mathrm{~min}$ followed by $40-45$ cycles of $95^{\circ} \mathrm{C}$ for $15 \mathrm{~s}$, and $60^{\circ} \mathrm{C}$ for $1 \mathrm{~min}$. For the TaqMan assay, both PCR primers and MGB TaqMan probes are shown in Table 1. The genotype analysis was performed by 2 persons independently blinded to the study. More than $15 \%$ of the samples were randomly selected for confirmation, and the discordance rate between genotypes was below $0.3 \%$. All SNPs were in Hardy-Weinberg equilibrium (HWE).

\section{Statistical Analysis}

Demographic characteristics were compared by Student's $t$ test (for continuous variables) and $\chi^{2}$ test (for categorical variables). Departure from HWE proportions of each SNP was tested by a goodness-of-fit $\chi^{2}$ test among controls. The abnormally distributed values were described by quartiles. Unconditional logistic regression analysis was performed to evaluate the effect of SNP genotypes on AR status, with age and sex as covariates; linear regression analysis was used to evaluate the effect of specific IgE level on AR outcome. Stratification analyses were performed by age, gender, asthma, and total IgE. $p<0.05$ was considered statistically significant. The Bonferroni method was used for multiple comparisons. All tests were 2-sided and performed with Statistical Analysis System software (version 9.1.3; SAS Institute, Cary, NC, USA) and Stata 8.2 statistical package (StataCorp LP, College Station, TX, USA). 
Table 3. Primary information of genotyped SNPs in microRNA target sites of TGF- $\beta$ signaling pathway genes

\begin{tabular}{|c|c|c|c|c|c|c|c|}
\hline \multirow[t]{2}{*}{ Target gene } & \multirow[t]{2}{*}{ SNPs } & \multirow[t]{2}{*}{ Location } & \multirow{2}{*}{$\begin{array}{l}\text { Base } \\
\text { change }\end{array}$} & \multicolumn{3}{|l|}{ MAF } & \multirow{2}{*}{$\begin{array}{l}p \text { value for } \\
\text { HWE test }\end{array}$} \\
\hline & & & & HapMap & Case & Control & \\
\hline TGFBR1 & rs1590 & 3'UTR & $\mathrm{T}>\mathrm{G}$ & 0.439 & 0.459 & 0.444 & 0.611 \\
\hline$B M P R 1 B$ & rs1434536 & 3'UTR & $\mathrm{C}>\mathrm{T}$ & 0.326 & 0.381 & 0.391 & 0.797 \\
\hline$B M P R 1 B$ & rs17023107 & 3'UTR & $\mathrm{C}>\mathrm{T}$ & 0.067 & 0.037 & 0.041 & 0.838 \\
\hline
\end{tabular}

SNPs, single-nucleotide polymorphisms; TGF- $\beta$, transforming growth factor beta; MAF, minor allele frequency; HWE, Hardy-Weinberg equilibrium.

Table 4. Genotype and allele frequencies of TGFBR1 and BMPR1B among cases and controls

\begin{tabular}{|c|c|c|c|c|c|c|}
\hline \multirow[t]{2}{*}{ Genotypes } & \multicolumn{2}{|c|}{ Cases } & \multicolumn{2}{|c|}{ Controls } & \multirow{2}{*}{$\begin{array}{l}\text { Crude OR } \\
(95 \% \mathrm{CI})\end{array}$} & \multirow{2}{*}{$\begin{array}{l}\text { Adjusted OR } \\
(95 \% \mathrm{CI})^{\mathrm{b}, \mathrm{c}}\end{array}$} \\
\hline & $n$ & $\%$ & $n$ & $\%$ & & \\
\hline \multicolumn{7}{|l|}{ TGFBR1 } \\
\hline rs1590 & \multicolumn{2}{|c|}{$n=453$} & \multicolumn{2}{|c|}{$n=446$} & & \\
\hline$T T$ & 127 & 28.0 & 140 & 31.4 & 1.00 & 1.00 \\
\hline$T G$ & 236 & 52.1 & 215 & 48.2 & $1.21(0.89-1.64)$ & $1.21(0.89-1.63)$ \\
\hline GG & 90 & 19.9 & 91 & 20.4 & $1.09(0.75-1.59)$ & $1.09(0.75-1.60)$ \\
\hline$T G / G G$ & 326 & 72.0 & 306 & 68.6 & $1.17(0.88-1.56)$ & $1.17(0.88-1.56)$ \\
\hline G allele ${ }^{\mathrm{a}}$ & & & & & $1.06(0.88-1.28)$ & $1.07(0.88-1.28)$ \\
\hline \multicolumn{7}{|l|}{$B M P R 1 B$} \\
\hline rs1434536 & \multicolumn{2}{|c|}{$n=452$} & \multicolumn{2}{|c|}{$n=442$} & & \\
\hline CC & 183 & 40.5 & 165 & 37.3 & 1.00 & 1.00 \\
\hline$C T$ & 194 & 42.9 & 208 & 47.1 & $0.84(0.63-1.21)$ & $0.84(0.63-1.21)$ \\
\hline$T T$ & 75 & 16.6 & 69 & 15.6 & $0.98(0.66-1.45)$ & $0.99(0.56-1.16)$ \\
\hline$C T / T T$ & 269 & 59.5 & 277 & 62.7 & $0.88(0.67-1.15)$ & $0.88(0.67-1.15)$ \\
\hline$T$ allele $^{\mathrm{a}}$ & & & & & $0.96(0.79-1.16)$ & $0.96(0.79-1.16)$ \\
\hline rs17023107 & \multicolumn{2}{|c|}{$n=454$} & \multicolumn{2}{|c|}{$n=446$} & & \\
\hline CC & 420 & 92.5 & 409 & 91.7 & 1.00 & 1.00 \\
\hline$C T$ & 34 & 7.5 & 37 & 8.3 & $0.90(0.55-1.45)$ & $0.92(0.57-1.50)$ \\
\hline$T T$ & 0 & 0.0 & 0 & 0.0 & - & - \\
\hline$C T / T T$ & 34 & 7.5 & 37 & 8.3 & $0.90(0.55-1.45)$ & $0.92(0.57-1.50)$ \\
\hline$T$ allele $^{\mathrm{a}}$ & & & & & $0.90(0.56-1.45)$ & $0.92(0.57-1.49)$ \\
\hline
\end{tabular}
test.

a Additive model. ${ }^{\mathrm{b}}$ Adjusted for age and gender in logistic regression model. ${ }^{\mathrm{c}}$ Thousand times permutation

\section{Results}

\section{Characteristics of the Subjects}

The characteristics of the studied population are presented in Table 2. A total of 454 mite-sensitized AR patients showed a median age of 15.0 (IQR, 11.0-26.0) years, including 304 (67.0\%) males and 150 (33.0\%) females. The 448 healthy controls had a median age of 15.5 (IQR, 9.9-29.0) years and 277 males (61.8\%) and 171 females
(38.2\%). There were no statistically differences in age or gender between 2 groups $(p>0.05)$.

Total serum IgE levels (284.0 [128.5-594.2] kU/L) in the patients were significantly higher than those in healthy controls (25.0 [10.4-47.4] kU/L) $(p<0.001)$. In AR patients, the serum levels of allergen-specific IgE against $\operatorname{Der} p$ and $\operatorname{Der} f$ were 29.7 (6.6-72.3) and 24.6 (6.2-66.9) $\mathrm{kU}_{\mathrm{A}} / \mathrm{L}$, respectively. 
Information of the Polymorphisms

The primary information and allele frequencies observed are summarized in Table 3. All genotyped distributions of control subjects were consistent with HWE $(p>0.05)$. In addition, the minor allele frequency of all the 3 SNPs were in accordance with that reported in the HapMap database of CHB (Han Chinese in Beijing, China).

\section{Association between Target SNPs and AR}

As shown in Table 4, the genotypic and allele frequency analysis of the selected SNPs (rs1590 in TGFBR1; rs1434536, and rs17023107 in BMPR1B) were not significantly associated with the susceptibility to mite-sensitized AR.

\section{Stratification Analysis in Subgroups}

The results of stratification analysis are shown in Table 5 . AR patients were divided into 4 subgroups by age, gender, presence of asthma, and total IgE levels. Compared with the wild-type TT genotype, the TG, GG, and TG/GG genotypes of rs 1590 in TGFBR1 exhibited a significantly increased risk of $A R$ in the subgroup of males (TG: adjusted $\mathrm{OR}=1.57,95 \% \mathrm{CI}=1.08-2.31$; GG: adjusted $\mathrm{OR}=1.76,95 \% \mathrm{CI}=1.09-2.86$; TG/GG: adjusted $\mathrm{OR}=1.62,95 \% \mathrm{CI}=1.13-2.33)$. Interestingly, the homozygote GG genotype of rs1590 exhibited a significantly decreased risk of AR in the subgroup of females (GG: adjusted $\mathrm{OR}=0.44,95 \% \mathrm{CI}=0.23-0.83$ ). As for the rs1434536 in BMPR1B, the CT genotype showed a significantly decreased risk of AR in the subgroup of patients without asthma (CT: adjusted OR $=0.70,95 \%$ $\mathrm{CI}=0.50-0.98$ ). Compared with the wild-type CC genotype, the CT genotype of rs17023107 in BMPR1B exhibited a significantly decreased risk of AR in the subgroup of age $<15$ years (CT: adjusted OR $=0.37,95 \%$ $\mathrm{CI}=0.14-0.95)$ and also in the subgroup of males (CT: adjusted $\mathrm{OR}=0.48,95 \% \mathrm{CI}=0.25-0.95)$. All the significances remained obvious after a thousand times of permutation tests. However, none of these SNPs in the TGF- $\beta$ pathway was correlated with the serum total IgE levels.

\section{Interaction Study}

The genotypes of rs1590, rs1434536, and rs17023107 were renamed as A1, A2, and A3, respectively. The multifactor dimensionality reduction software was used to assess the joint effects of the 3 SNPs in TGFBR1 and $B M P R 1 B$. As presented in Table 6, no significant associations were detected between the 3 selected SNPs.

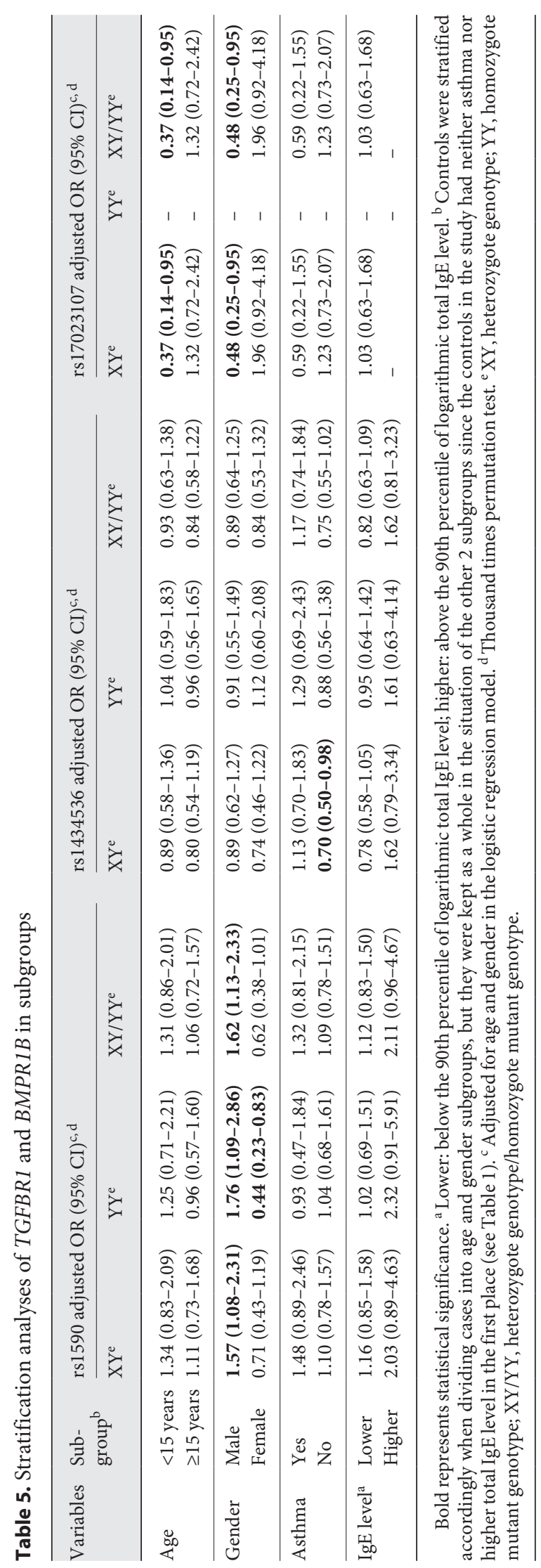

Int Arch Allergy Immunol 2021;182:399-407 DOI: $10.1159 / 000511975$
MicroRNA Target Site SNPs of TGF- $\beta$

Pathway and Allergic Rhinitis 


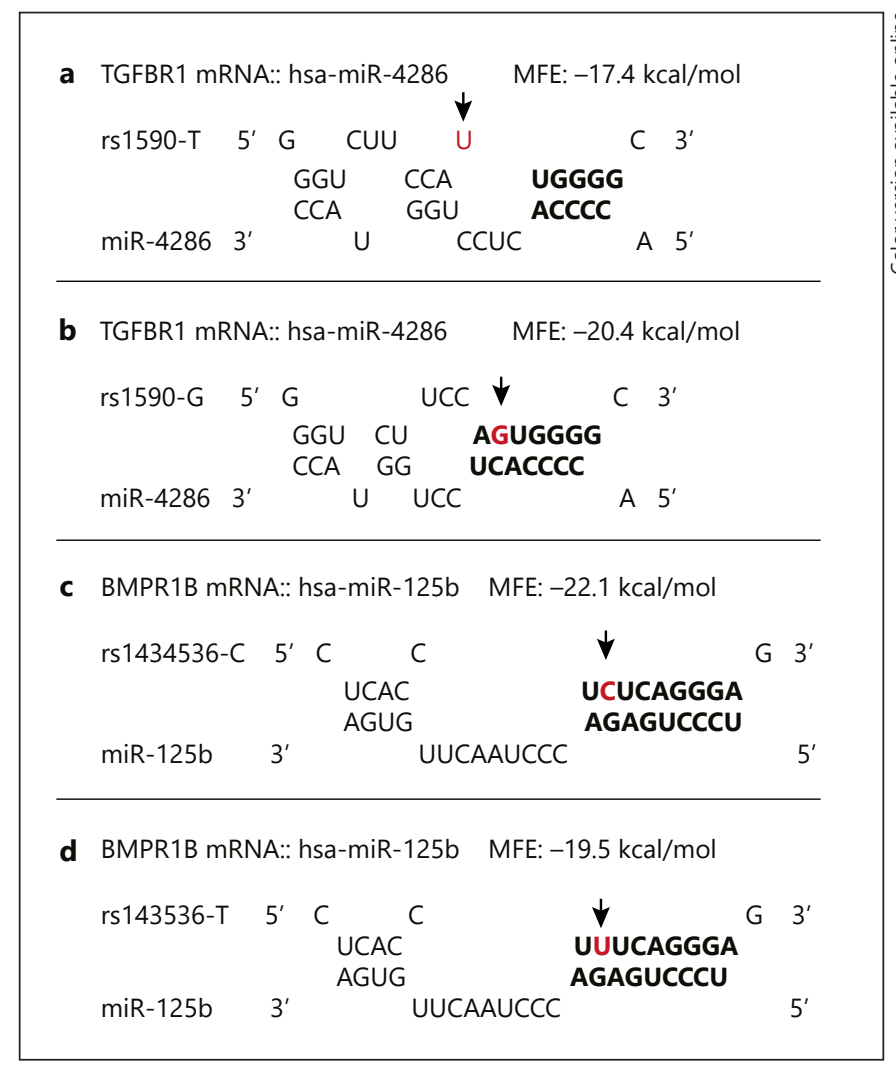

Fig. 1. Predicted binding of miR-4286 to TGFBR1 (a, b) and miR$125 \mathrm{~b}$ to $B M P R 1 B(\mathbf{c}, \mathbf{d})$. The seed region of the target site is shown in bold letter and every SNP is indicated by an arrow. The MFE of the RNA duplex was analyzed by RNA hybrid. MFE, minimum free energy.

\section{Discussion}

The airway inflammation is regulated by a network of mutually interacting cytokines and effector cells in asthma or rhinitis that could be triggered by genetic and environmental factors [31]. TGF- $\beta$ represents a master switch in inflammation and remodeling processes in both the upper and lower airways [32]. Experimental studies show that the effect of TGF- $\beta$ is decided by its level, but also some regulatory proteins [33]. Ierodiakonou et al. [34] indicated that TGFB1 SNPs could influence serum TGF- $\beta 1$ serum level and asthma severity.

Genetic variants of TGF- $\beta$ signaling pathway genes are implicated in the development of allergic disease, yet only a few studies have further investigated how these variants relate to specific dysfunction $[35,36]$. MicroRNAs are dysregulated in various human diseases, such as cancer, rheumatoid arthritis, asthma, rhinosinusitis, and AR [37]. So far, none has delved into the roles of microRNA-
Table 6. MDR models for locus-locus interactions

\begin{tabular}{|c|c|c|c|c|}
\hline Model $^{\mathrm{a}}$ & $\begin{array}{l}\text { Training balance } \\
\text { accuracy }\end{array}$ & $\begin{array}{l}\text { Test balance } \\
\text { accuracy }\end{array}$ & $\begin{array}{l}\text { Cross-validation } \\
\text { consistency }\end{array}$ & $p$ value \\
\hline $\mathrm{A} 2$ & 0.5253 & 0.4815 & $6 / 10$ & 0.8281 \\
\hline A1 A2 & 0.5322 & 0.5004 & $10 / 10$ & 0.6230 \\
\hline $\mathrm{A} 1 \mathrm{~A} 2 \mathrm{~A} 3$ & 0.5351 & 0.4832 & $10 / 10$ & 0.9990 \\
\hline
\end{tabular}

MDR, multifactor dimensionality reduction. ${ }^{\text {a }}$ The genotypes of rs1590, rs1434536, and rs17023107 were renamed as A1, A2, and $\mathrm{A} 3$, respectively.

related SNPs in AR. The present study evaluated the contribution of the polymorphisms inside microRNA target sites in $3^{\prime}$-UTR of TGF- $\beta$ pathway to mite-sensitized AR susceptibility in a Han Chinese population. Using bioinformatic tools, we obtained TGFBR1 rs1590T/G, $B M P R 1 B \mathrm{rs} 1434536 \mathrm{C} / \mathrm{T}$, and $\mathrm{rs} 17023107 \mathrm{C} / \mathrm{T}$ as target SNPs that may modify (increase/decrease) the binding affinity of putative microRNA-mRNA duplexes.

TGFBR1 (56 kb in length and consisting of 9 exons) maps to $9 \mathrm{q} 22.33$. Functioning as the central propagator of TGF- $\beta$ signaling, TGFBR1 encodes a serine/threonine protein kinase receptor. We employed RNA hybrid [38] to model the targeting between specific microRNA and TGFBR 1 mRNA. According to the minimum free energy, miR-4286 was more stably bound to rs $1590-\mathrm{G}$ allele than to 1590 -T allele (Fig. 1). These results are consistent with those in DNA microarray in the nasal mucosa, showing that attenuated TGF- $\beta$ signaling may contribute to AR [39]. Polymorphisms in $3^{\prime}$-UTRs may decrease mRNA stability and interfere with its translation through disrupting microRNA-mRNA interaction and polyadenylation in protein-mRNA [40]. Moreover, allele-specific expression could reduce the expression of genes encoding TGFBR 1 in TG mutants [41]. Although subtle, the reduction in constitutive TGFBR1 expression may alter Smadmediated TGF- $\beta$ signaling and AR pathophysiology. Collectively, these data point out that repressed TGF- $\beta$ signaling contributes to AR risk. However, we cannot rule out the chance that TGF- $\beta$ signaling is also enhanced in a critical developmental stage and/or cell type-specific manner.

In this study, we found lack of association between the TGFBR 1 and BMPR1B polymorphisms and the susceptibility of mite-sensitized AR in a Han Chinese population. However, it has been proposed that the effects of polymorphisms may rely on factors such as age, sex, and eth- 
nicity. Compared with the wild-type TT genotype, the TG, GG, and TG/GG genotypes of TGFBR1 rs1590 exhibited a significantly increased risk of AR in the subgroup of males. On the contrary, the GG genotype of rs 1590 exhibited a significantly decreased risk of AR in the subgroup of females. Moreover, compared with the wild-type CC genotype, the CT genotype of BMPR1B rs17023107 exhibited a significantly decreased risk of AR in the subgroup of males. The significant association between the 2 SNPs and AR in subgroups of gender may result from the interaction between the genotypes and sexual hormones. It has been reported that estrogen can suppress the function of bone morphogenetic proteins (BMPs) by interfering with Smad transcriptional activity and by inhibiting $B M P$ gene expression [42].

BMPs are a body of conserved signaling molecules from TGF- $\beta$ superfamily [43]. BMPs can lead to tumorigenesis and regulate cancer progression in different stages [44]. In a mouse model of asthma, BMP receptors were activated upon allergen provocation in the airway epithelium [45], suggesting BMP signaling may be involved in the tissue repair and inflammatory processes. As shown in Figure 1, it suggested that replacing $C$ allele by $\mathrm{T}$ allele reduced binding ability of miR-125b to $B M P R 1 B$ mRNA. In the present study, rs $1434536 \mathrm{C} / \mathrm{T}$ in the $B M P R 1 B$ gene showed no association with AR risk. However, in the subgroup of AR without asthma, we found a significant decreased risk of AR in the CT genotype of rs1434536. Compared with the wild-type genotype $\mathrm{CC}$, the $\mathrm{CT}$ genotype of rs17023107 in BMPR1B exhibited a significantly decreased risk of AR in the subgroup of age $<15$ years old. The reason may be that the immune system of the adolescent has not fully developed.

$\mathrm{IgE}$ is an atopy-related quantitative trait; however, the underlying mechanisms remain incompletely defined [46]. TGF- $\beta$ can downregulate the T helper 2 response to reduce IgE release. Serum total IgE and eosinophil cationic protein were found significantly associated with TGFB1 rs1800469 [47]. In the present study, the TGFBR1 genotypes did not show a significantly multiplicative interaction effect with $B M P R 1 B$ genotypes for AR risk. That might be explained by the complexity of immune mechanism. In the bronchial inflammation of asthmatics, IgE synthesis is realized by several biological networks that could modulate the effects of TGF- $\beta 1$ on IgE production [14].

Major strengths of this study include a stratified study design, a large sample size and a comprehensive analysis of TGF- $\beta$ pathway genes. However, limitations should also be considered. First, only the Smad-dependent
TGF- $\beta$ pathway was evaluated. Second, the effect of environmental and genetic polymorphisms was ignored. Environmental influence is a crucial factor in the progression of allergic diseases. More research on gene-environment interaction is needed in the future.

In summary, our data suggested that in this Han Chinese population stratified by age and gender, the susceptibility of mite-sensitized AR may be associated with 2 SNPs (rs1590 in TGFBR1 and rs17023107 in BMPR1B) inside microRNA target sites of TGF- $\beta$ signaling pathway genes. Larger, better-designed studies are to be carried out using appropriate molecular and statistical methods to further analyze this functional association.

\section{Acknowledgements}

We are grateful to the participants in this study and all staff involved in the study through the years. The authors thank Associate Professor Yong-Ke Cao at the College of Foreign Languages of Nanjing Medical University for his support and work in the professional English-language proofreading of the manuscript.

\section{Statement of Ethics}

This study has been reviewed and approved by the Ethics Committee of Nanjing Medical University (20080305).

\section{Conflict of Interest Statement}

None of the authors have a conflict of interest in relation to this work. The authors have no ethical conflicts to disclose.

\section{Funding Sources}

This study was supported by the grants from the National Natural Science Foundation of China (81200747 and 81800890).

\section{Author Contributions}

L.C., R.-X.C., and W.-M.L. mainly designed the study. R.-X.C., W.-M.L., M.-P.L., X.-J.Z., Z.-F.W., H.-Q.T., and L.-P.Z. collected and compiled the data. R.-X.C. and W.-M.L. performed the statistical analysis and drafted the manuscript. M.-L.W. and Z.-D.Z. provided the technical support for the experiment. All authors jointly discussed, reviewed, and amended the manuscript. All authors reviewed the final manuscript version and consented to its submission. 


\section{References}

1 Mims JW. Epidemiology of allergic rhinitis. Int Forum Allergy Rhinol. 2014 Sep;4(Suppl 2):S18-20.

2 Zhang L, Han D, Huang D, Wu Y, Dong Z, Xu $\mathrm{G}$, et al. Prevalence of self-reported allergic rhinitis in eleven major cities in china. Int Arch Allergy Immunol. 2009;149(1):47-57.

3 Wang XD, Zheng M, Lou HF, Wang CS, Zhang Y, Bo MY, et al. An increased prevalence of self-reported allergic rhinitis in major Chinese cities from 2005 to 2011. Allergy. 2016 Aug;71(8):1170-80.

4 Cheng L, Chen J, Fu Q, He S, Li H, Liu Z, et al. Chinese Society of Allergy Guidelines for diagnosis and treatment of allergic rhinitis. Allergy Asthma Immunol Res. 2018 Jul;10(4): 300-53.

5 Perry MM, Adcock IM, Chung KF. Role of microRNAs in allergic asthma: present and future. Curr Opin Allergy Clin Immunol. 2015 Apr;15(2):156-62.

6 Shi Y, Fu X, Cao Q, Mao Z, Chen Y, Sun Y, et al. Overexpression of miR-155-5p inhibits the proliferation and migration of IL-13-induced human bronchial smooth muscle cells by suppressing TGF- $\beta$-activated kinase 1/MAP3K7binding protein 2. Allergy Asthma Immunol Res. 2018 May;10(3):260-7.

7 Nickel J, Ten Dijke P, Mueller TD. TGF- $\beta$ family co-receptor function and signaling. Acta Biochim Biophys Sin. 2018 Jan 1;50(1): $12-36$.

8 Goumans MJ, Ten Dijke P. TGF- $\beta$ signaling in control of cardiovascular function. Cold Spring Harb Perspect Biol. 2018 Feb 1;10(2): a022210.

9 Zi Z. Molecular engineering of the TGF- $\beta$ signaling pathway. J Mol Biol. 2019 Jul 12; 431(15):2644-54.

10 Lee HY, Kim IK, Yoon HK, Kwon SS, Rhee CK, Lee SY. Inhibitory effects of resveratrol on airway remodeling by transforming growth factor- $\beta /$ smad signaling pathway in chronic asthma model. Allergy Asthma Immunol Res. 2017 Jan;9(1):25-34.

11 Samitas K, Carter A, Kariyawasam HH, Xanthou G. Upper and lower airway remodelling mechanisms in asthma, allergic rhinitis and chronic rhinosinusitis: the one airway concept revisited. Allergy. 2018 May;73(5):9931002.

12 Singer AJ, Clark RA. Cutaneous wound healing. N Engl J Med. 1999 Sep 2;341(10):73846.

13 Hansen G, McIntire JJ, Yeung VP, Berry G, Thorbecke GJ, Chen L, et al. CD4(+) T helper cells engineered to produce latent TGF-beta1 reverse allergen-induced airway hyperreactivity and inflammation. J Clin Invest. 2000 Jan;105(1):61-70.
14 Acevedo N, Vergara C, Gusmão L, Jiménez S, Martínez B, Mercado D, et al. The C-509T promoter polymorphism of the transforming growth factor beta-1 gene is associated with levels of total and specific IgE in a Colombian population. Int Arch Allergy Immunol. 2010; 151(3):237-46.

15 Zhang Y, Zhang J, Huang J, Li X, He C, Tian $\mathrm{C}$, et al. Polymorphisms in the transforming growth factor-betal gene and the risk of asthma: a meta-analysis. Respirology. 2010 May; 15(4):643-50.

16 Yucesoy B, Kashon ML, Johnson VJ, Lummus ZL, Fluharty K, Gautrin D, et al. Genetic variants in TNFa, TGFB1, PTGS1 and PTGS2 genes are associated with diisocyanate-induced asthma. J Immunotoxicol. 2016;13(1): $119-26$.

17 Zhu XJ, Lu MP, Chen RX, Bu DY, Zhu LP, Wang ML, et al. Polymorphism -509C/T in TGFB1 promoter is associated with increased risk and severity of persistent allergic rhinitis in a Chinese Population. Am J Rhinol Allergy. 2020 Sep;34(5):597-603.

18 Suzuki H. MicroRNA control of TGF- $\beta$ signaling. IJMS. 2018 Jun 28;19(7):1901.

19 Moszynska A, Gebert M, Collawn JF, Bartoszewski R. SNPs in microRNA target sites and their potential role in human disease. Open Biol. 2017 Apr;7(4):170019.

20 Gao F, Xiong X, Pan W, Yang X, Zhou C, Yuan Q, et al. A regulatory MDM4 genetic variant locating in the binding sequence of multiple microRNAs contributes to susceptibility of small cell lung cancer. PLoS One. 2015;10(8):e0135647.

21 Stegeman S, Moya L, Selth LA, Spurdle AB, Clements JA, Batra J. A genetic variant of MDM4 influences regulation by multiple microRNAs in prostate cancer. Endocr Relat Cancer. 2015 Apr;22(2):265-76.

22 Suojalehto H, Toskala E, Kilpeläinen M, Majuri ML, Mitts C, Lindström I, et al. MicroRNA profiles in nasal mucosa of patients with allergic and nonallergic rhinitis and asthma. Int Forum Allergy Rhinol. 2013 Aug;3(8): 612-20.

23 Li L, Zhang S, Jiang X, Liu Y, Liu K, Yang C. MicroRNA-let-7e regulates the progression and development of allergic rhinitis by targeting suppressor of cytokine signaling 4 and activating Janus kinase 1 /signal transducer and activator of transcription 3 pathway. Exp Ther Med. 2018 Apr;15(4):3523-9.

24 Hu D, Zhang Z, Ke X, Kang H, Hong S. A functional variant of miRNA-149 confers risk for allergic rhinitis and comorbid asthma in Chinese children. Int J Immunogenet. 2017 Apr;44(2):62-70.

25 Trinh HKT, Pham DL, Kim SC, Kim RY, Park HS, Kim SH. Association of the miR-196a2, miR-146a, and miR-499 polymorphisms with asthma phenotypes in a Korean population. Mol Diagn Ther. 2017 Oct;21(5):547-54.
26 Bousquet J, Khaltaev N, Cruz AA, Denburg J, Fokkens WJ, Togias A, et al. Allergic rhinitis and its impact on asthma (ARIA) 2008 update (in collaboration with the World Health Organization, GA(2)LEN and AllerGen). Allergy. 2008 Apr;63(Suppl 86):8-160.

27 Garcia DM, Baek D, Shin C, Bell GW, Grimson A, Bartel DP. Weak seed-pairing stability and high target-site abundance decrease the proficiency of lsy- 6 and other microRNAs. Nat Struct Mol Biol. 2011 Sep 11;18(10): 1139-46.

28 Hiard S, Charlier C, Coppieters W, Georges M, Baurain D. Patrocles: a database of polymorphic miRNA-mediated gene regulation in vertebrates. Nucleic Acids Res. 2010 Jan; 38(Database issue):D640-51.

29 Ziebarth JD, Bhattacharya A, Chen A, Cui Y. PolymiRTS Database 2.0: linking polymorphisms in microRNA target sites with human diseases and complex traits. Nucleic Acids Res. 2012 Jan;40(Database issue):D216-21.

30 Gong J, Tong Y, Zhang HM, Wang K, Hu T, Shan G, et al. Genome-wide identification of SNPs in microRNA genes and the SNP effects on microRNA target binding and biogenesis. Hum Mutat. 2012 Jan;33(1):254-63.

31 Ngoc PL, Ngoc LP, Gold DR, Tzianabos AO, Weiss ST, Celedón JC. Cytokines, allergy, and asthma. Curr Opin Allergy Clin Immunol. 2005 Apr;5(2):161-6.

32 Yang YC, Zhang N, Van Crombruggen $\mathrm{K}, \mathrm{Hu}$ GH, Hong SL, Bachert C. Transforming growth factor-betal in inflammatory airway disease: a key for understanding inflammation and remodeling. Allergy. 2012 Oct; 67(10):1193-202.

33 Kaminski N, Allard JD, Pittet JF, Zuo F, Griffiths MJ, Morris D, et al. Global analysis of gene expression in pulmonary fibrosis reveals distinct programs regulating lung inflammation and fibrosis. Proc Natl Acad Sci U S A. 2000 Feb 15;97(4):1778-83.

34 Ierodiakonou D, Postma DS, Koppelman GH, Gerritsen J, ten Hacken NH, Timens W, et al. TGF- $\beta 1$ polymorphisms and asthma severity, airway inflammation, and remodeling. J Allergy Clin Immunol. 2013 Feb;131(2): 582-5.

35 Sandford AJ. Asthma susceptibility: the role of transforming growth factor beta1. Respirology. 2010 May;15(4):583-4.

36 Costa RD, Figueiredo CA, Barreto ML, Alcantara-Neves NM, Rodrigues LC, Cruz AA, et al. Effect of polymorphisms on TGFB1 on allergic asthma and helminth infection in an African admixed population. Ann Allergy Asthma Immunol. 2017 Apr;118(4):483-8.e1.

37 Dissanayake E, Inoue Y. MicroRNAs in allergic disease. Curr Allergy Asthma Rep. 2016 Sep;16(9):67. 
38 Tan Z, Randall G, Fan J, Camoretti-Mercado B, Brockman-Schneider R, Pan L, et al. Allelespecific targeting of microRNAs to HLA-G and risk of asthma. Am J Hum Genet. 2007 Oct;81(4):829-34.

39 Benson M, Carlsson B, Carlsson LM, Mostad P, Svensson PA, Cardell LO. DNA microarray analysis of transforming growth factor-beta and related transcripts in nasal biopsies from patients with allergic rhinitis. Cytokine. 2002 Apr 7;18(1):20-5.

40 Nicoloso MS, Sun H, Spizzo R, Kim H, Wickramasinghe $P$, Shimizu $M$, et al. Single-nucleotide polymorphisms inside microRNA target sites influence tumor susceptibility. Cancer Res. 2010 Apr 1;70(7):2789-98.
41 Valle L, Serena-Acedo T, Liyanarachchi S, Hampel H, Comeras I, Li Z, et al. Germline allele-specific expression of TGFBR1 confers an increased risk of colorectal cancer. Science. 2008 Sep 5;321(5894):1361-5.

42 Takahashi M, Otsuka F, Miyoshi T, Otani H, Goto J, Yamashita M, et al. Bone morphogenetic protein 6 (BMP6) and BMP7 inhibit estrogen-induced proliferation of breast cancer cells by suppressing p38 mitogen-activated protein kinase activation. J Endocrinol. 2008 Dec;199(3):445-55.

43 Estevez M, Attisano L, Wrana JL, Albert PS, Massagué J, Riddle DL. The daf-4 gene encodes a bone morphogenetic protein receptor controlling C. elegans dauer larva development. Nature. 1993 Oct 14;365(6447):644-9.
44 Zhang L, Ye Y, Long X, Xiao P, Ren X, Yu J. BMP signaling and its paradoxical effects in tumorigenesis and dissemination. Oncotarget. 2016 Nov 22;7(47):78206-18.

45 Kariyawasam HH, Xanthou G, Barkans J, Aizen M, Kay AB, Robinson DS. Basal expression of bone morphogenetic protein receptor is reduced in mild asthma. Am J Respir Crit Care Med. 2008 May 15;177(10):1074-81.

46 Weidinger S, Gieger C, Rodriguez E, Baurecht H, Mempel M, Klopp N, et al. Genome-wide scan on total serum IgE levels identifies FCER1A as novel susceptibility locus. PLoS Genet. 2008 Aug;4(8):e1000166.

47 Dennler S, Goumans MJ, ten Dijke P. Transforming growth factor beta signal transduction. J Leukoc Biol. 2002 May;71(5):731-40. 